\title{
Immunological Relationships of Glucose-6-Phosphate Dehydrogenase of Leuconostoc mesenteroides NCDO 768 (=ATCC 12291)
}

\author{
FRANCIS GASSER AND MIREILLE HONTEBEYRIE \\ Unité de Physiologie Cellulaire, Départment de Biochimie et Génétique Microbienne, Institut Pasteur, 75015 \\ Paris, France
}

An antiserum against the purified glucose-6-phosphate dehydrogenase (EC 1.1.1.49) (G-6-P-DH) of Leuconostoc mesenteroides NCDO 768 has been prepared. Cross-reactions were observed with extracts of other strains of Leuconostoc, comprising named strains of $L$. lactis, $L$. mesenteroides, $L$. dextranicum, $L$. cremoris, and $L$. paramesenteroides. Cross-reactions were not obtained with $L$. oenos. The groups of identical specificity and their order of decreasing similarity toward the homologous enzyme were determined, and the results are consistent with those obtained previously with another G-6-P-DH antiserum from L. lactis NCDO 546. Thus, except for $L$. oenos, many strains of Leuconostoc comprising multiple (three or more) species might be considered as phenotypically diverse but genetically rather uniform in their line of descent from a common ancestor.

Previously (4), we purified to a state of electrophoretic homogeneity (3) two distinct isofunctional enzymes-D-lactate dehydrogenase (D-LDH, EC 1.1.1.28) and glucose-6-phosphate dehydrogenase (G-6-P-DH, EC 1.1.1.49)-from Leuconostoc lactis NCDO 546 (3). The pure enzymes from this strain were used separately as immunogens to prepare anti-D-LDH and antiG-6-P-DH sera. Crude extracts were prepared from 50 strains of Leuconostoc comprising $L$. cremoris (two strains), L. lactis (nine strains), $L$. paramesenteroides (nine strains), L. dextranicum (six strains), L. mesenteroides (19 strains), L. oenos (five strains) and 13 strains of heterofermentative members of Lactobacillus comprising $L$. brevis (two strains), L. buchneri (one strain), $L$. fermentum (three strains), $L$. viridescens (one strain), unnamed heterofermentative strains (six strains), and one strain of the homofermentative species, $L$. jensenii. Any cross-reactions produced by these crude extracts in the presence of appropriate pure antisera were studied by a double agar diffusion method whose experimental conditions were described previously $(2,4,5)$. There were no detectable cross-reactions between the $\mathrm{D}$ LDH and G-6-P-DH antigen-antisera systems from $L$. lactis NCDO 546. None of the extracts from the Lactobacillus strains reacted with either antisera. There were seven groups of antigenic specificity (A to G) for the D-LDH and six groups (a to f) for the G-6-P-DH. The important fact was that (except for $L$. oenos) the grouping pattern for the Leuconostoc strains was exactly the same for both enzymes.

In this paper, we describe the immunological
TABLE 1. Groups of identical antigenic specificity obtained with the serum anti-G-6-P-DH from leuconostoc mesenteroides NCDO $768^{a}$

\begin{tabular}{lc}
\hline \multicolumn{1}{c}{ Nomenspecies } & $\begin{array}{c}\text { Immuno- } \\
\text { logical } \\
\text { group }\end{array}$ \\
\hline $\begin{array}{l}\text { Leuconostoc lactis } \\
\text { NCDO 532-533-534-535 }\end{array}$ & $\mathrm{a}^{\prime}$ \\
NCDO 536-546-549-956-959 & \\
Leuconostoc mesenteroides & $\mathrm{b}^{\prime}$ \\
CIP 54171-NCIB 3351 & \\
Leuconostoc mesenteroides & $\mathrm{d}^{\prime}$ \\
NCIB 9317-8013-9319-8710 & \\
NCDO 522-523 & \\
ATCC 10830-V16, 1533 & \\
CIP 54168, 54170 & \\
Le 512-13-Le 512-17-Le 513-17-Le 513-12 & \\
Leuconostoc dextranicum & $\mathrm{d}^{\prime}$ \\
NCDO 571-529-812 & \\
NCIB 3739-2706-3356 & \\
Leuconostoc cremoris & $\mathrm{d}^{\prime}$ \\
NCDO 543-829 & \\
Leuconostoc mesenteroides & $\mathrm{e}^{\prime}$ \\
NCDO 768-882 & \\
Leuconostoc paramesenteroides & \\
NCDO 803-870-871-872-873 & $\mathrm{f}^{\prime}$ \\
NCDO 885-886-955-CIP 54169 & \\
Leuconostoc oenos & \\
ATCC 23278-WL D1-WL BG31 & No ross- \\
WL B6-WL LA1-SC 122 & reaction \\
\hline
\end{tabular}

${ }^{a}$ These groups were determined by pairwise comparison of crude extracts located in adjacent wells on Ouchterlony plates. The production of a continuous line of precipitate without spur formation indicates the appurtenance to a same group of specificity. Group $\mathrm{e}^{\prime}$ is the homologous group since it gathers strains, extracts of which do not produce a spur against the homologous enzyme purified from strain NCDO 768. Group $c^{\prime}$ is not represented in this table since it contains only one strain, NCIB 9317, which is included in the group $d^{\prime}$. The symbol $c^{\prime}$, however, has been kept by analogy with the previous findings (4). 


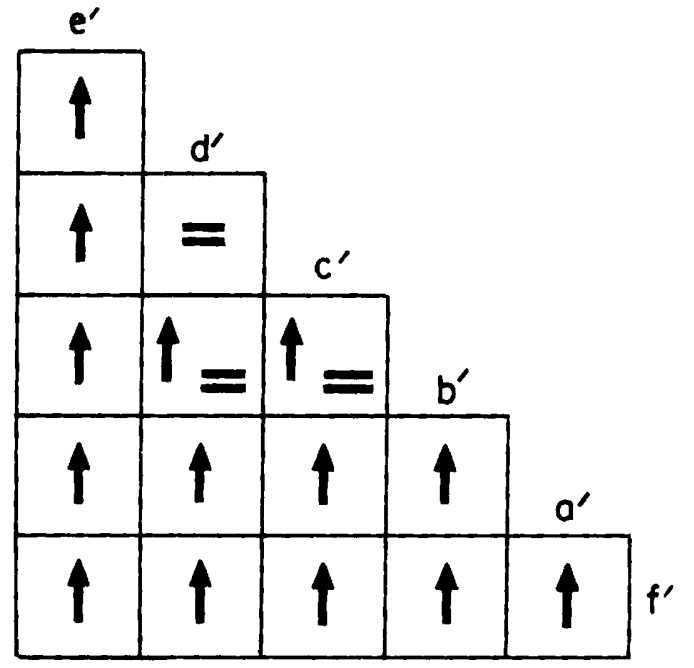

FIG. 1. Hierarchy of immunological relatedness of the different groups of identical specificity of Leuconostoc G-6-P-DH, based on precipitin cross-reaction with G-6-P-DH antiserum of $L$. mesenteroides NCDO 768. By definition, extracts of strains of different groups of identical specificity produce a continuous line of precipitin and a spur against the antiserum when they are placed in two adjacent wells of an Ouchterlony plate. The direction of the arrow indicates the groups, the extract of which produces the spur in the paired comparison. The equal sign indicates that no spur occurs in such a comparison.

cross-reactions obtained with another G-6-PDH antiserum produced against the enzyme of a strain of group e, $L$. mesenteroides NCDO 768 (ATCC 12291). This strain is one of the suggested reference strains for this species cited in the 8th edition of Bergey's Manual (1). Its G-6P-DH was purchased from Sigma Chemical Co. (reference G 2256) and repurified by preparative polyacrylamide gel electrophoresis as described previously $(3,5)$. One band of protein was obtained after analytical electrophoresis in polyacrylamide gel of $120 \mu \mathrm{g}$ of purified enzyme. The antiserum obtained with this material produced a single line of precipitin against a crude extract of $L$. mesenteroides NCDO 768 submitted to a 2-h immunoelectrophoretic run (4). Experimental conditions and interpretations were the same as employed previously (2, 4,5 ).

All the crude extracts of the strains of Leuconostoc tested gave a precipitin line with the G-6-P-DH antiserum except extracts of $L$. oenos (recognized as group G with $\mathrm{D}-\mathrm{LDH}$ antiserum from L. lactis NCDO 546 [4]). This lack of cross-reactivity already observed is related to a low enzyme activity in our extracts. Among lactobacilli, only Lactobacillus viridescens produced a cross-reaction.
Table 1 shows that the 50 strains of Leuconostoc can be arranged into six groupings ( $\mathrm{a}^{\prime}$ to $f^{\prime}$ ) of identical antigenic specificity, containing the same strains within each group whether the homologous G-6-P-DH system was from the group a-L. lactis NCDO 546 - (4) or whether the homologous system was from the group $\mathrm{e}^{\prime}-$ $L$. mesenteroides NCDO 768 (ATCC 12291), as in the present work.

Figure 1 shows the direction of the spurs obtained between the different groups of identical specificity. The spurs between the $b^{\prime}$ and $d^{\prime}$ groups and between the $b^{\prime}$ and $e^{\prime}$ groups were always weak and were not produced between all the extracts tested. From this table we deduce the following order of decreasing similarity toward the homologous enzyme: $e^{\prime}>d^{\prime}=c^{\prime}$ $>\mathrm{b}^{\prime}>\mathrm{a}^{\prime}>\mathrm{f}^{\prime}$.

This order is consistent with the result previously obtained with the G-6-P-DH antiserum of L. lactis NCDO 546 (group a): $a>c>b>d>e$ $>\mathrm{f}$. The relative position of group a toward group $f$ and of group $a^{\prime}$ toward group $f^{\prime}$ suggests that a double spur might have been expected between groups $d$ and $f$.

We may note that such a double spur was obtained with the D-LDH antiserum from $L$. lactis NCDO 546 (4) which displays this order of decreasing similarity: $A>B>C>(D / F)>E$. These results confirm the great similarity of groups (B), (C), (D) in terms of phylogeny of their D-LDH and G-6-P-DH as revealed by their respective immunological cross-reactivity. Not only do they always appear as neighbors in all orders of similarities but they sometimes fail to produce any spur as in the case of $b^{\prime}, d^{\prime}$, and $c^{\prime}$.

(C)

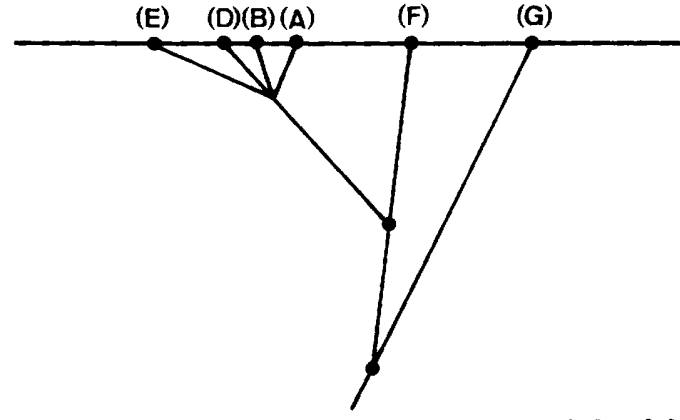

(F) (G)

Fig. 2. Relative evolutionary position of the different groups of identical antigenic specificity organized in a hypothetical phylogenic tree as suggested by the immunological relationships of the $D-L D H$ and the G-6-P-DH enzymes in the genus Leuconostoc. Underlined letters totalizes the different groups symbolized by the corresponding letter: for example (A) totalizes the groups $A, \alpha$, and $a^{\prime}$. Group (G) ( $L$. oenos) is determined with the $D-L D H$ antiserum only since its extracts do not produce a cross-reaction with G-6-P-DH antisera. 
These convergent results for two different enzymes suggest a hypothetic phylogenic tree (Fig. 2).

\section{ACKNOWLEDGMENTS}

We wish to thank Geneviève Chévrier for his valuable technical assistance. This work was supported by research funds of University Paris VII.

\section{REPRINT REQUESTS}

Address reprint requests to: Dr. Francis Gasser, Unité de Physiologie Cellulaire, Départment de Biochimie et Génétique Microbienne, Institut Pasteur, 28 Rue du Docteur Roux, 75015 Paris, France.

\section{LITERATURE CITED}

1. Garvie, E. I. 1974. Genus Leuconostoc van Tieghem, p. 510. In R. E. Buchanan, and N. E. Gibbons (ed.),
Bergey's manual of determinative bacteriology, 8th ed. The Williams \& Wilkins Co. Baltimore.

2. Gasser, F., and C. Gasser. 1971. Immunological relationships among lactic dehydrogenases in the genera Lactobacillus and Leuconostoc. J. Bacteriol. 106:113125.

3. Hontebeyrie, M., and F. Gasser. 1973. Séparation et purification de la D-lacticodéshydrogénase et de la glucose-6-phosphate déshydrogénase de Leuconostoc lactis. Etude de quelques propriétés. Biochimie 55:1047-1056.

4. Hontebeyrie, M., and F. Gasser. 1975. Comparative immunological relationships of two distinct sets of isofunctional dehydrogenases in the genus Leuconostoc. Int. J. Syst. Bacteriol. 25:1-6.

5. London, J., and K. Kline. 1973. Aldolase of lactic acid bacteria: a case history in the use of an enzyme as an evolutionary marker. Bacteriol. Rev. 37:453-478. 